\title{
Natural language mediation and covert rehearsal in short-term memory
}

LOWELL D. GRONINGER

UNIVERSITY OF ILLINOIS

The short-term effects of natural language mediators and covert repetitions were studied using high and low meaningfulness $\mathrm{CCC}_{S}$ with a presentation time of 2 sec., a retention interval of $30 \mathrm{sec}$, and an interpolated activity of counting backward by threes. Each $S$ was given four items of the same level of meaningfulness. There were $96 \mathrm{Ss}$ in each group. $\mathrm{NLM}_{s}$ and covert rehearsal were both significant factors in recall. $\mathrm{NLM}_{S}$ were found to deter proactive inhibition.

Keppel \& Underwood (1962) were the first to show that interference factors operate in short-term memory (STM) in a fashion qualitatively similar to long-term memory. Several later studies have investigated various parameters of interference in STM (Loess, 1964; Waugh \& Norman, 1965; Wickens, Born, \& Allen, 1963; Neimark et al, 1965). However, still another type of interference parameter is suggested by findings in the psychological literature that Ss freely use many types of natural language mediators $\left(\mathrm{NL}_{\mathrm{S}}\right.$ ) in the learning of verbal materials (e.g., Montague, Adams, \& Kiess, in press)。 For example, a S might impose "Hamlet" or "Her mother's tiara" on the syllable HMT when it is presented. If this kind of associating is done with any regularity, the response entity (syllable and NLM) from one STM learn-recall sequence to another should be relatively dissimilar and should reduce proactive inhibition (PI). If this reasoning is correct, then items on which $\mathrm{NLM}_{\mathbf{S}}$ are reported should show little forgetting over trials, while items on which no $\mathrm{NLM}_{\mathrm{S}}$ are reported should show a forgetting curve similar to that of Keppel \& Underwood (1962) and Loess (1964). The present study was designed to evaluate the role of NLM formation on PI in STM. A secondary goal of the present study was the evaluation of covert rehearsal which may occur during the conventional interpolated activity of counting backwards.

Method

The design had two independent variables: (1) meaningfulness (M) determined by association value from Witmer's list of $\mathrm{CCC}_{\mathrm{S}}$ in Underwood \& Schulz (1960), and (2) number of preceding items. Two groups were formed: Group $\mathrm{H}$, which had items of high $M$ ( $92 \%$ association value), and Group $\mathrm{L}$, which had items of low $\mathrm{M}$ (25\% association value). The stimulus items were 16 randomly selected $\mathrm{CCC}_{\mathrm{S}}$ at each $\mathrm{M}$ level. There were 96 undergraduate Ss randomly assigned to each group.

Each $\mathrm{S}$ was given four items which were presented to him on 3 in. $x 5$ in. cards. The order of presentation of items was randomized (by shuffling). However, the cards were not shuffled until all 16 in the set were presented, thus assuring that every card was shown an equal number of times. All Ss were briefly instructed about $\mathrm{NLM}_{\mathrm{S}}$ but were not urged to use them. The $\mathrm{S}$ was given a $4 \mathrm{sec}$. warning before an item was shown. A presentation time of $2 \mathrm{sec}$. was used, during which the $\mathrm{S}$ was required to spell the item aloud. After the 2 sec. had elapsed, a 3-digit number was spoken and the $\mathbf{S}$ was required to count backward from that number as rapidly as possible for $30 \mathrm{sec}$. At the end of the 30 sec. counting period, the word "Recall" was spoken, and the $\mathrm{S}$ was given $12 \mathrm{sec}$. in which to recall the item. After the recall period, the $S$ was asked whether he made any association (NLM) when he first saw the trigram and what type it was, and also if the word "came to him" while he was counting (covert rehearsal). The criterion for NLM formation was whether or not the $S$ could verbalize any aid he used to facilitate recall. After the interviewing period, the ready signal was spoken again, and the procedure repeated.

Resulis

Figure 1 shows the percentage of Ss on each trial who reported $\mathrm{NLM}_{\mathrm{S}}$ or covert rehearsal. Covert re-

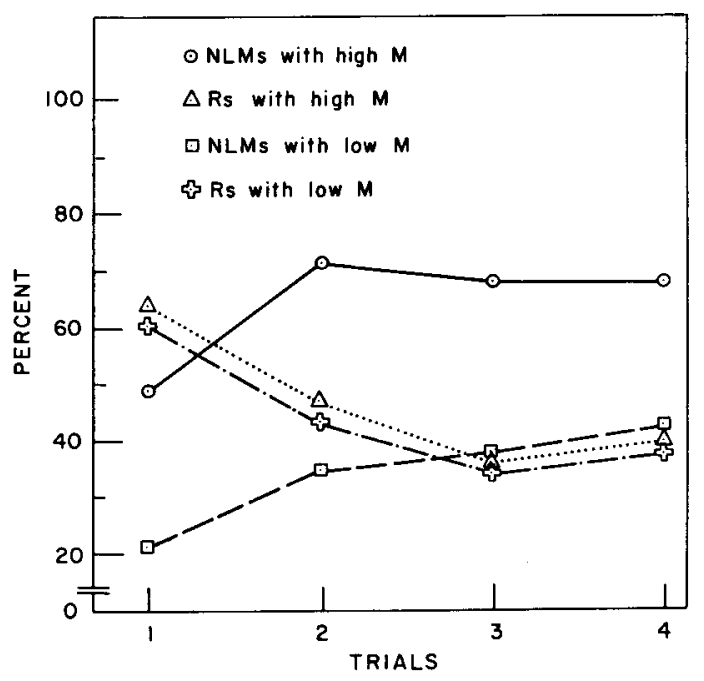

Fig. 1. Percent of $96 \mathrm{Ss}$ on each trial who reported covert repetitions $\left(R_{S}\right)$ and $\mathrm{NLM}_{\mathrm{S}}$ for high and low meaningfulness $(\mathrm{M}) \mathrm{CCC}_{\mathrm{S}}$. 


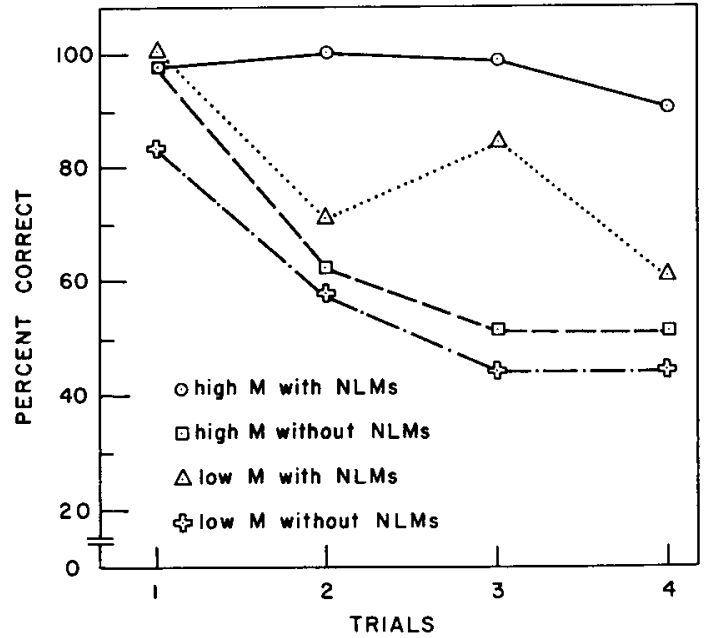

Fig. 2. Effects of $\mathrm{NLM}_{\mathrm{S}}$ (averaged over covert repetitions) on recall of high and low meaningfulness $(\mathrm{M}) \mathrm{CCC}_{\mathbf{5}} \cdot{ }^{2}$

hearsal generally decreases and $\mathrm{NLM}_{S}$ generally increase with trials.

Figure 2 shows the effect of $\mathrm{NLM}_{\mathrm{S}}$ on recall as a function of trials. The effectiveness of $\mathrm{NLM}_{\mathrm{S}}$ in maintaining high recall is most dramatically shown by Group $H . N_{S}$ formed in Group $L$ show the same beneficial trend but to a lesser extent. The standard PI forgetting function in STM appears for both high and low $\mathrm{M}$ items when $\mathrm{NLM}_{\mathbf{S}}$ are absent. Chi-square tests between NLM formation and correctness were highly significant for both groups.

The type of NLM formed was typically simple, as would be expected from the short presentation time. Imposing a word on the trigram or representing the trigram by familiar initials constituted most of the cases.

Covert rehearsal was related significantly to correctness at recall, with the rehearsed items in both groups showing better retention. However, there was no interaction between the effects of covert rehearsal and trials.

\section{Discussion}

The data confirm Keppel \& Underwood (1962) and Loess (1964) that a primary source of forgetting in STM is $\mathrm{PI}_{s}$ stemming from the number of prior learnrecall sequences with similar materials. An important finding of this experiment is that $\mathrm{NLM}_{\mathrm{S}}$ benefit retention by deterring PI. On Trial 1, all items have very high retention whether they have a NLM or not (Fig. 1), but on subsequent trials a NLM is required to maintain high retention. Items without a NLM show considerable forgetting and the expected PI effect. A reasonable explanation is that the trigram plus its NLM is a new verbal entity with relative uniqueness and power to resist the interfering effects of prior items.

Figure 1 illustrates the difficulty of preventing covert rehearsal by the standard procedure of counting backwards. The covert rehearsal occurred in the present study in spite of instructions to "concentrate fully on counting during this period." In STM studies where the elimination of covert rehearsal is mandatory, new methodological techniques seem required.

\section{References}

Keppel, G., \& Underwood, B. J. Proactive inhibition in short-term retention of individual terms. J. verbal Learn. verbal Behav., 1962, 1, 153-161.

Loess, H. Proactive inhibition in short-term memory. J. verbal Learn. verbal Behav., 1964, 3, 362-368.

Montague, W. E., Adams, J. A., \& Kiess, H. O. Forgetting and and natural language mediation. $J$. exp. Psychol., in press.

Neimark, E., Greenhouse, P., Low, S., \& Weinheimer, S. The effect of rehearsal-preventing tasks upon retention of CVC syllables. $J$. verbal Learn. verbal Behav., 1965, 4, 280-285.

Underwood, B. J., \& Schultz, R. W. Meaningfulness and verbal learning. New York: Lippincott, 1960.

Waugh, N. C., \& Norman, D. A. Primary memory. Psychol. Rev. $1965,75,89-105$.

Wickens, D. O., Born, D. G., \& Allen, C. K. Proactive inhibition and item similarity in short-term memory. $J$. verbal Learn. verbal Behav., 1963, 1, 440-445.

\section{Notes}

1. This study is based on research submitted in partial fulfillment of the Masters of Arts degree at the University of Illinois. The study was supervised by Jack A. Adams, and partly supported by NIH Grant 12022.

2. Considering the four curves successively from top to bottom, the $\mathrm{N}$ on each trial was: $47,69,67,67 ; 49,27,29,29 ; 19,32,36$, $41 ; 77,64,60,55$. 